\title{
Exploring the Importance of Changing the Culture Within Healthcare Towards the Underreporting of Medical Errors: A Systematic Review
}

\author{
Lyndon Garvin Augustine, Ph.D. \\ School of Business Analytics and Decision Sciences, Capitol Technology University \\ 11301 Springfield Rd, Laurel, MD 20708, United States
}

Received: Feb. 11, 2021 Accepted: Mar. 12, 2021 Online published: Apr. 6, 2021

doi:10.5296/ijhrs.v11i2.18501ＵRL: https://doi.org/10.5296/ijhrs.v11i2.18501

\begin{abstract}
The ethical dilemma for the healthcare industry is that although they strive to keep patients safe, the culture reflects an underreporting of medical errors. Because of this, healthcare leaders have strived relentlessly to create a positive patient safety culture. A positive patient safety culture alludes to traits within a company that permit patient safety to be a goal, including open reporting, a no blame environment to incident reporting, dedicated leadership, continuous companywide learning, and a take charge recognition of safety warnings.

Despite the efforts to create this type of safety culture, based on findings within this study, the conclusion is that leaders within the healthcare community have failed to foster this form of culture. Because of this, the objective of this study was to explore the importance of changing the culture within healthcare towards the underreporting of medical errors. In terms of methodology used to explore a culture change, the researcher performed a literature review. As for the results towards addressing a culture change, the researcher identified three barriers. Thereafter, the researcher provided resolutions to overcome these barriers.
\end{abstract}

Keywords: medical errors, culture, patient safety

\section{Introduction}

"To err is human" is a well-known saying that captures the fallibility of human beings. Humans are fallible and as such, they will make mistakes in their lives and work whether they are engineers, builders, bankers, educators, or doctors (Edwin, 2009). In the field of medicine, a medical error can be defined as either the lack of successfully executing a planned action that was desired as intended or the use of an incorrect plan to achieve a goal. Errors can be noted from complications, which are non-preventable adverse events resulting 
from medical interventions. Medical errors are frequently categorized based on whether their outcomes get to the patient or not. Those medical errors not getting to the patient, either by odds, fixed intervention, or safety barricade, are referred to as nearby misses. Those getting to the patient but not imposing harm are often cited as innocuous hits (Kohn, 1999).

However, medical errors that reaches the patient and inflicting harm are referred to as harmful errors. According to Sorrell (2017), ethical concerns linked to medical errors can be partitioned around four ethical truths: (1) Autonomy and Right to Self Determination Refers to ideas around self-reliance and right to self-determination to acknowledge patients' rights to make their own decisions and to take steps based on their own views and benefits. (2) Beneficence and Nonmaleficence - The truths of beneficence and nonmaleficence lead healthcare professionals to do what is best for patients and to help circumvent harm. (3) Disclosure and Right to Knowledge - Healthcare professionals have an ethical commitment to reveal information that patients need for informed decision-making. (4) Veracity - The concern of veracity demands healthcare professionals to reveal complete, precise, and unbiased information in a fashion that assists patients comprehend the information (Sorrell, 2017).

\section{Method}

The purpose of this research was to explore the importance of changing the culture within healthcare towards the underreporting of medical errors. Because of this, Simon and Goes (2013) stated that performing an extensive literature review should be the underlining objective when performing a study (p. 277). What's more, Simon and Goes stated that the literature review is a blended critical essay that examines and unifies the most relevant and current published knowledge on the topic under investigation. Knowing this, the researcher performed a literature review, which resulted with a series of resolutions as a guide to help curtail the underreporting of medical errors.

\section{Results}

\subsection{Developing a Patient Safety Culture}

The science of medicine is built upon "First, do no harm" principle. Although this principle is true, according to Sandars (2007), it took a landmark Harvard study that showed that the fatalities equal to a single jumbo-jet crash per day was transpiring as an immediate result of preventable injury in U.S. hospitals to really get the attention of the public. However, in spite of this study, it took another ten years to get the world's interest in medical errors (Sandars, 2007). More specifically, the launch of the Institute of Medicine's (IOM) influential report To Err is Human: Building a Safer Health System in 2000, is what really gave momentum to medical errors (Heher, 2018).

Since then, there has thereafter been a surge to originate patient safety initiatives in several countries globally, especially within the United States (U.S.). For instance, within the U.S., The American Recovery and Reinvestment Act (ARRA) of 2009 devoted $\$ 22$ billion to the promotion of health care information technology (IT) to help mitigate medical errors from happening (Lee, 2016). The latter echoes the observation from DeGeorge (2003) in which the 


\section{Ml Macrothink}

International Journal of Human Resource Studies

ISSN 2162-3058

2021, Vol. 11, No. 2

author stated, "IT has changed and will increasingly change the way business is done" (p. 3). Because of these efforts, the change in patient safety has ensued in a global program of policy development, leading up to the establishment of the World Health Organization's World Alliance for Patient Safety. See e.g., Fig 1.1 below for World Health Organization's World Alliance for Patient Safety.

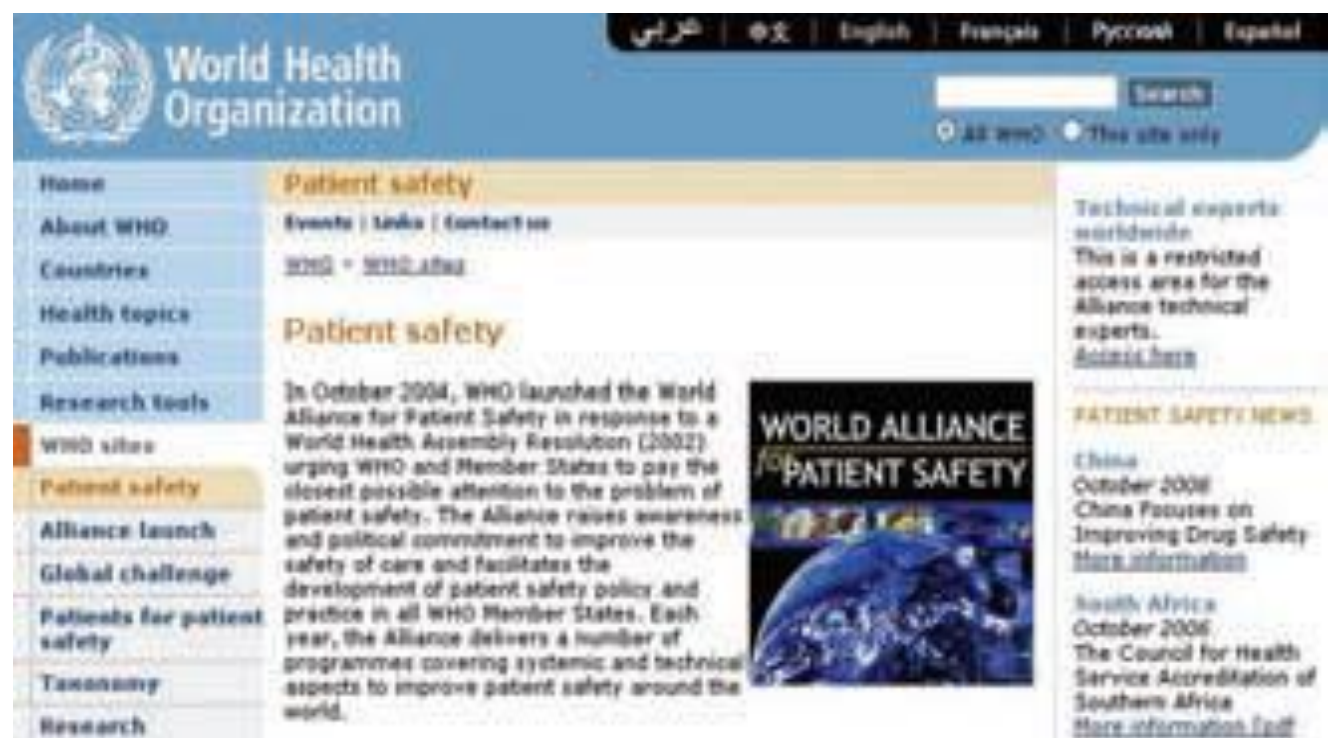

Figure 1.1. The World Health Organization's World Alliance for Patient Safety represents an important international advance (Sandars, 2007)

As defined by Davies (2003), patient safety is the reduction and mitigation of unsafe acts within the health care system, as well as through the use of best practices shown to lead to optimal patient outcomes. In addition, creating a patient safety culture is interpreted as the by-product of individual and group principles, frame of mind, understandings, capabilities, and forms of behavior that shape the dedication to, and the form and competency of, an organization's health and safety management (Health and Safety Commission Advisory Committee on the Safety of Nuclear Installations, 1993).

As such, patient safety culture refers to the standards, frame of mind, and behaviors within an organization that set out to endorse patient safety. A positive patient safety culture refers to a number of attributes within a health care organization that permits patient safety to be a precedence, including open communication, a no blame perspective to incident reporting, dedicated leadership, continuous organizational learning, and the take-charge recognition of safety warnings (Sandars, 2007).

\subsection{Background on Medical Errors}

A Medical error is interpreted as an unintended physical injury resulting from or contributed to by medical care which requires additional monitoring, treatment, hospitalization, or that may even result in death. In comparison, The IOM interpreted a medical error as: (i) the failure of a planned action to be completed as intended or (ii) the use of a wrong plan to achieve an aim. Given these definitions, the National Patient Safety Foundation in the USA 
classify medical errors into three subcategories: (i) errors of commission (doing the wrong thing), (ii) errors of omission (not doing the right thing), and (iii) errors of execution (doing the right thing incorrectly) (Kalender, 2020, p. 2).

Despite the severity outlined within the various definitions above, medical errors continue to threaten patient safety in healthcare practices. For example, patient safety specialists at Johns Hopkins have computed that over 250,000 deaths occur each year in the U.S. due to medical errors (McMains, 2016). In another study, Ugur (2016) reported that in the United States, avoidable medical errors account for between 210,000 to 440,000 deaths each year (p. 593). Equally important, Zineldin (2014) further argued that more people either die or are injured by medical errors than by diseases (e.g., AIDS, cancers, etc.) within the U.S.

With this conclusion conversely, Nagarajan (2017) came to a similar conclusion in reporting that medical errors were considered the third leading cause of death in the U.S., after heart disease and cancer. This coincides with McMains (2016) study in that in 2013, the Centers for Disease Control and Prevention ranked the top three causes of death as heart disease, cancer, and respiratory disease. However, in 2016, researchers at Johns Hopkins found that medical errors replaced respiratory disease as the third leading cause of death (McMains, 2016).

What's more, when compared to other countries, data revealed that the U.S. had the highest number of preventable deaths, with France and Australia being the lowest (Nolte \& McKee, 2011). As for Canada, it was reported that out of the 2.5 million admissions per year, 185,000 of them were linked to an adverse event (Bishop, 2015). Because of this, the Canadian Patient Safety Institute (CPSI) was formed in 2003 with the goal of improving patient safety in Canada.

In another example, Sandars (2007) reported that more than 85,000 negligent adverse events occur each year in English hospitals. Granted that, only 6,000 new medical negligence claims were addressed each year. Given this data from within the U.S, United Kingdom, and Canada, one can conclude that there is a need to have effective mechanisms in place to prevent medical errors and to strive to improve patient safety.

\subsection{Contributing Factors Leading to Medical Errors}

Medical errors negatively affect patients, healthcare professionals, and healthcare organizations. Therefore, all healthcare associates should be alert to medical errors. To this end, research has disclosed that most medical errors are caused by the system, rather than by individuals (Kalender, 2020). Knowing this, Ugur (2016) conducted a descriptive study that was planned to investigate medical errors taking place in the operating room. This study consisted of 69 staff members (30 physicians, 17 nurses, 10 anesthesia technicians, and 12 as others). In terms of the top four contributing factors that was cited as causing patient safety medical errors, they were as followed: (1) inadequate staff qualifications (2) insufficient communication and flow of information; (3) Time constraint and fast pace of work; and (4) Fatigue and stress due to long working hours (p. 595).

Although most medical errors are caused by system breakdowns, Patel (2018) conducted 
another study that focused on the consequences related to physician burnout. Physician burnout is a world-wide dilemma that is seen in healthcare professionals, particularly physicians, and is identified by emotional exhaustion, depersonalization, and a feeling of low personal accomplishment. In this study, it was noted that $25 \%-60 \%$ of physicians disclosed some type of exhaustion across various specialties. In fact, the results of the survey showed that $54.4 \%$ of the US physicians in 2018 cited at least one symptom of burnout when compared with $45.5 \%$ in 2011. The study concluded that the consequences of physician burnout can lead to the failures related to interpersonal relationships, increased medical errors, increased risk of malpractice, reduced patient satisfaction, and the quality of care and patient outcomes (Patel, 2018). Given the results from each of the above related studies related to known contributing factors of medical errors, one can conclude that there needs to be remedies in place to help avoid medical errors from occurring.

\subsection{Remedies Towards Preventing Medical Errors}

Ugur (2016) highlighted that one solution that must be implemented to reduce errors before surgery is to hold team meetings so that successful communication can be carried out to assess each patient in detail. In addition to this collaboration, having a stable team where individuals know each other well will reduce staff changes, increase team satisfaction and also will lessen medication errors, which subsequently will result in a surge of patient safety. Equally important, Ugur argued that conducting out time-out procedures, which can last between 1-4 minutes on the average, can also increase patient safety by 93\% (p. 596). In summary, when it comes to patient safety implementations, Ugur concluded that activities such as assembling teamwork meetings, offering educational programs, constructing an uncomplicated reporting system, enhancing communication between the disciplines, and inspiring medical staff to report medical errors may boost patient safety within the operating room setting (p. 593).

In terms of addressing physician burnout, as noted by Patel (2018), physician burnout is a significant problem in the medical profession, but it can be reversible and preventable. As a remedy, Patel noted that there is a need for top management to keep a check on physicians' physical and mental well-being, which can be achieved through self-awareness programs or surveys. Such programs among physicians can enhance the ability to recognize their vulnerability to burnout, fatigue, stress, and accentuate resiliency. This can be addressed by the systematic application of evidence-based interventions, including but not limited to group interventions, mindfulness training, assertiveness training, facilitated discussion groups, and encouraging a healthy work environment.

\subsection{Barriers Towards Underreporting of Medical Errors}

A patient safety culture requires a process based on questioning and improving the system instead of punishing individuals. In other words, judgmental and punitive attitudes from top management has been noted as important reasons of not reporting problems related with patient safety. With that said, as noted by the IOM, the biggest challenge to moving toward a safer health system is changing the culture from one of blaming individuals for errors to one in which errors are treated not as personal failures, but as opportunities to improve the system 
and prevent harm (Nieva, 2003). Because of this current culture of being punitive, this has created an ethical dilemma for the healthcare industry in that although they strive to keep patients safe, the culture reflects an underreporting of medical errors.

To illustrate, as highlighted by Nieva (2003), adverse event reporting systems will not overcome chronic underreporting problems within a punitive culture where acknowledgement of error is not acceptable. Nieva further cited that analytical methods such as root cause analysis (RCA) and failure mode effects analyses (FMEA) will not succeed in uncovering latent sources of error if staff, bound by an implicit "code of silence" and a fear of challenging the institutional hierarchy, are uncomfortable with exposing weaknesses in processes for which they are responsible. The author highlighted that even benefits from new technologies designed to improve safety, such as computerized physician order entry, may not be realized if they are not accompanied by cultural and process changes (Nieva, 2003, p. 17).

Hence, here lies the first barrier pertaining to the ethical dilemma of underreporting of medical errors for the healthcare industry, and that is, healthcare systems may seek to improve patient safety but they are unwilling to move away from the current "blame and shame" culture that prevents acknowledgement of error and therefore obstructs any possibility of learning from error. Sandars (2007) arrived at the same conclusion in stating that to produce a patient safety culture, healthcare organizations must implement a blameless viewpoint to incident reporting.

This conclusion is valid because as purported by Archer (2017), the forming and execution of incident reporting systems within healthcare has continued to be a key plan of action to minimize preventable patient harm and enhance the quality and safety of healthcare on a national, regional and local basis. In fact, Archer argued that even though coverage and refinement varies broadly, incident-reporting processes have now been in position for over a decade in a number of countries. Nevertheless, the author concluded that a major component that affects the capability of incident reporting systems to improve patient safety is under-reporting, which is mainly due to the "blame and shame" culture.

This blame and chastising of a recognized malefactor are habitual retorts to safety incidents (Wu, 2017). As an illustration, patients were questioned about the appropriate action to a hypothetical deadly medication error often approved punishment, and $69 \%$ of surveyors thought that the physician should be sued for malpractice, and 50\% thought that the physicians' license should be debarred temporarily (Wu, 2017, p. 44). As reported by Wu (2017), the blame instinctive is also sustained by the media's astonishing coverage of medical errors, which tends to highlight the shortcomings of individuals over key systems breakdowns, strengthening the existing medical culture of anxiety around the revelation of medical errors.

For these reasons, this ethical duty for healthcare professionals to report medical errors as part of their mission to enhance patient safety has been suboptimal, which is a by-product of the "current "blame and shame" culture". To demonstrate, in the U.S., it is estimated that $50 \%-96 \%$ of incidents are not reported and the top barrier was the blame and shame culture (Noble, 2010). Moreover, from this study, the second top barrier cited for not reporting 
medical errors was broken processes and systems.

As an illustration, Hickman (2017) concluded that Computerized Prescriber Order Entry (CPOE) systems have been broadly promoted as a way to minimize such errors. However, these systems may also initiate errors, and the National Academy of Medicine has proposed that studies should be performed to better comprehend errors related to health information technology in general, and electronic prescribing especially. In addition to the blame and shame culture, and broken processes and systems, a third barrier pertaining to the ethical dilemma of underreporting medical errors for the healthcare industry was the lack of transparency and open communication.

Transparency, interpreted as the free, unrestrained exchange of information, has been promoted as probably the most salient aspect of a culture of safety (Bell, 2017). Despite this definition, evidence concerning transparency between doctors and patients, amid peers, or between providers and institutions when things go incorrect are moderately little. Transparent conveying after medical error includes revealing the mistake to the patient, talking the event through with colleagues, and disclosing it to the institution. Bell (2017) noted that comprehending physician perspective about transparency is key to advocating open and sincere communication after adverse events to halt errors and to learn from miscalculations when they transpire (p. 243).

Kim (2017) cited that even though physicians maintain that medical errors should be made known to patients and their families, they often pause to do so because they feel uncomfortable due to fear of legal action, blame, and declaring medical error to a patient. In fact, research shows that disclosure of error is abnormal, with approximately $30 \%$ being revealed. Although documentation reenforces that patients are more likely to sue physicians when there is no honest communication, numerous physicians are fearful that revealing medical errors to patients will bring about legal action. With this in mind, various hospital executives and risk management professional still say that physicians should not apologize to patients because an apology is viewed as an admission of fault (Kim, 2017).

Kim also argued that ethical intricacies in error revelation also account for disclosure gaps in that there are unsure circumstances whether unforeseen end result was caused by a medical error and because of this, physicians tend to pause to reveal errors to patients when errors caused either insignificant or no harm although they believe fatal errors should be revealed to patients. In addition, there has been small consensus about whether or not to reveal errors to patients when detrimental errors involve patients who could not live longer regardless of errors (Kim, 2017, p. 4). Hence, because of these complexities, the Institute of Medicine (2000) argued that the problem in medical errors is not caused due to awful people working in health care settings, but in contrast is the result of good people working in awful systems.

For this reason, there is a need to make the systems safer, the need to improve communication, and the need for precise lines of authority of physicians, nurses, and other healthcare providers. In other words, the institute of medicine concluded that fragmented reporting systems within a hospital causes serious disruptions in coordination and patient results. This conclusion was similar to Nobel (2010) in which the author cited broken 
processes and systems of reporting as an issue towards underreporting medical errors. To illustrate this complex system provided by the Institute of Medicine, see e.g., figure 1.2 below for complexity in healthcare systems illustration.

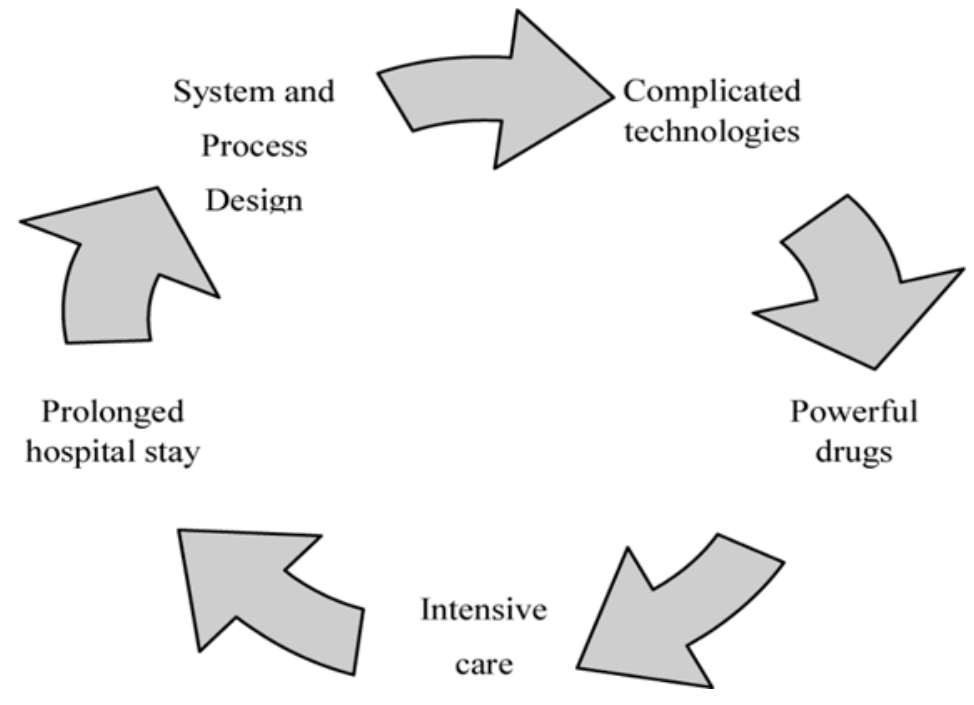

Figure 1.2. Complexity in healthcare systems (Nagarajan, 2017)

\section{Discussion}

To this end, given the barriers towards the ethical dilemma on why the healthcare industry is underreporting medical errors - blame and shame culture; broken processes and systems of reporting, lack of transparency and open communication, - the main question that needs to be asked is, what actions are needed to make an impact to address this dilemma?

\section{Resolution \#1 - address the blame and shame culture}

As purported by Sandars (2007), the biggest barrier working in the direction to a safer health system is reforming the culture from one of blaming individuals for errors to one in which errors are treated not as personal deficiencies, but as opportunities to enhance the system and put a stop to adverse events (p. 22). For starters, every organization develops its own culture - that is, the way on how processes and procedures are carried out. The culture of an organization is frequently apparent when an organization is confronted (Sandars, 2007). In this case, the culture encompasses of the shared perspectives, optimisms, morals and suppositions that arise from how people within the healthcare community go about their assignments. The very same belief also pertains to underreporting of medical errors. Hence, the first step towards addressing the underreporting of medical errors is to achieve a cultural change within the healthcare community. The goal is to transcend from a blame and shame culture to a just culture.

To move forward with this effort, Heher (2018) concluded that regulatory bodies such as the Joint Commission for the Accreditation of Healthcare Organizations (JCAHO), the Accreditation Councils on Graduate and Continuing Medical Education (ACGME), and physician organizations including the College of American Pathologists need to push hospitals, physicians, and training programs to embrace quality and safety philosophies 


\section{Macrothink}

International Journal of Human Resource Studies

ISSN 2162-3058

2021, Vol. 11, No. 2

through ordinances. Likewise, insurers and governmental payers need to embrace payment models that promotes safety culture objectives and landmarks (Heher, 2018).

As highlighted by Sandars (2007), cultural change is interested with how individuals perceive and ponder about issues. Which is to say, occasions have to be produced for individuals to openly declare their opinions, and this openness then needs to be conveyed to processes that permit all individuals to disclose and talk about adverse events. A just culture can give individuals a chance to disclose and talk about medical errors without worry of retribution. However, on the contrary, it does not exonerate individuals from being liable for their activities because a prime feature of expanding a safety culture is to confirm that individuals regard themselves as being personally, and inclusively, answerable for safety.

For this reason, Wu (2017) believed that modifying vocabulary could also assist to reposition the frame of minds and assumptions for both patients and providers toward a more cultivated comprehension of patient safety. For instance, in 2008, Canada embraced the use of the expression patient safety incident and harmful incident in favor to error. This perspective mirrors the actuality that injury is normally not due to error by a single health care professional. Wu concluded that working towards vocabulary that is less likely to give rise to blame could assist to fine tune beliefs for both patients and clinicians and expedite prompt revelations and supportive determinations (p. 45).

\section{Resolution \#2 - address the broken processes and systems of reporting}

As noted, processes for documenting medical errors have been in place for decades, with the desire that the composed reports would aid us to comprehend the creation of errors and fend off kindred errors from happening in the future. Among the various types of reporting systems, a voluntary system leaves the decision about whether to report a detected error or not to healthcare providers. Naturally, not every detected error has been reported, and we call such a phenomenon under-reporting (Jeong, 2017). To help overcome these gaps and broken processes, Jeong (2017) suggested using a computerized prescriber order entry (CPOE) system as an example

To examine the impact of CPOE on errors, the author added the odds ratios from prescribing and administering errors reported from hospitals with CPOE, as indicated by the dark grey bars in e.g., Figure 1.3 below. 


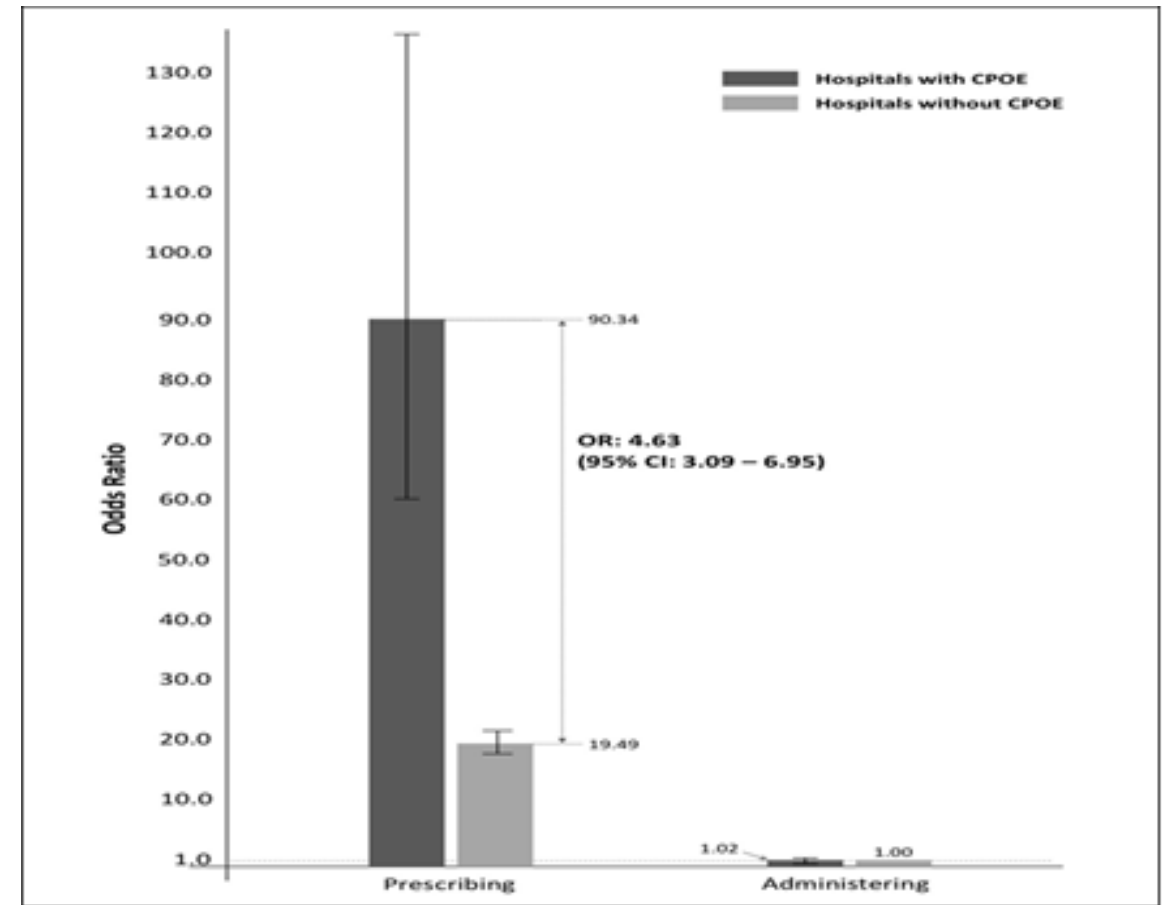

Figure 1.3. The effectiveness of CPOE in each node on catching errors before reaching the patient (Jeong, 2017)

In addition to employing a computerized prescriber order entry (CPOE) system, Heher (2018) suggested that that the healthcare industry needs to rely more on the Root Cause Analysis flow chart to improve the process of reporting errors. See e.g., Figure 1.4 below.

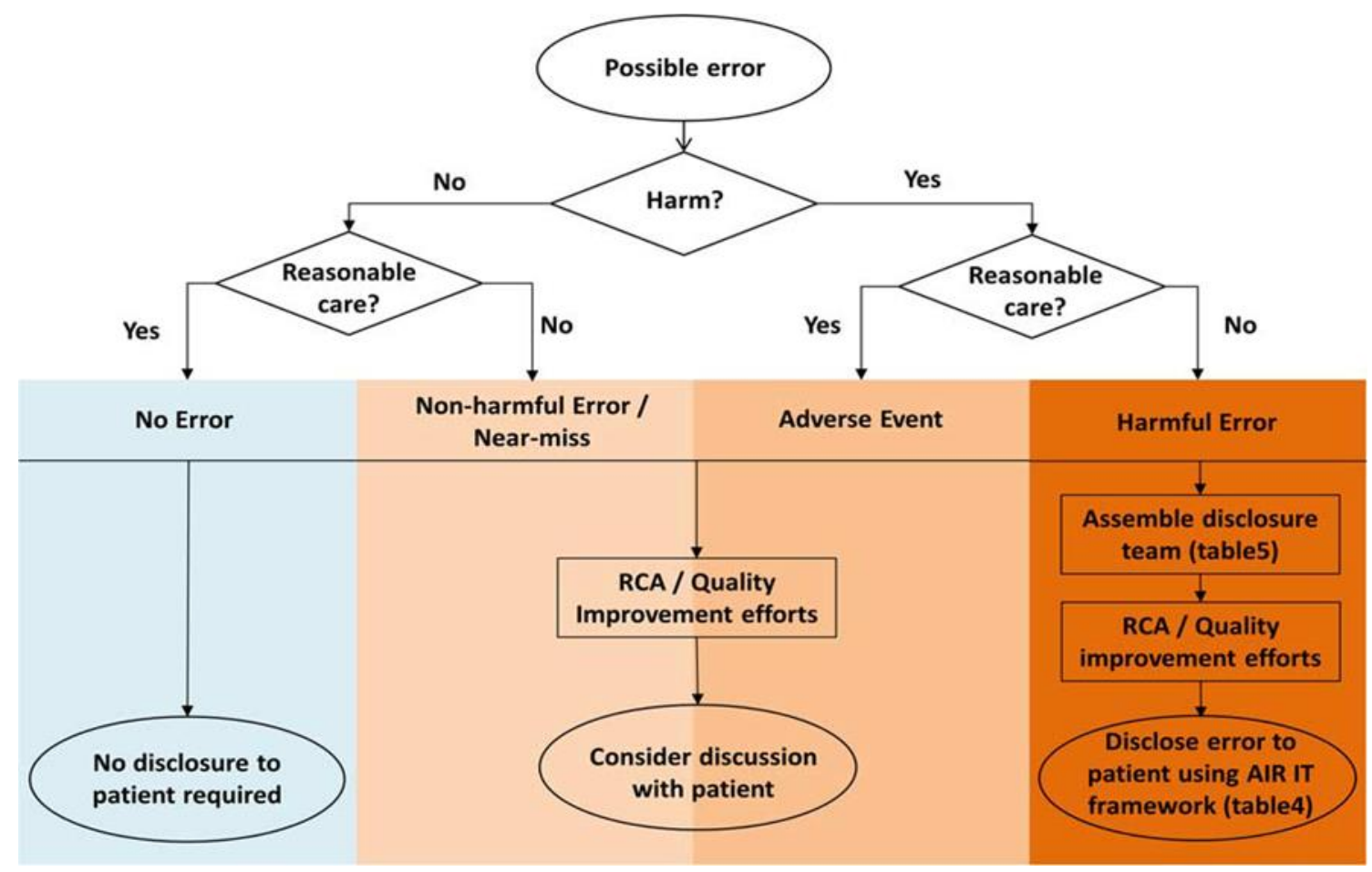

Figure 1.4. Disclosure flowchart. RCA: root cause analysis (Heher, 2018) 


\section{Resolution \#3 - address the lack of transparency and open communication}

Crystal clear communication after medical errors includes revealing the mistake to the patient, talking about the event with colleagues, and relaying the event to the institution (Bell, 2017). With that said, Kim (2017) concluded that edifying physicians and other health care professionals is the first step to building a culture of straightforwardness and open communication. The reason for this conclusion is that there is a likelihood for physicians to lessen their communication with patients following an adverse event, because they often feel blameworthy and are fearful about the potential for a grievance (Sandars, 2007). Contrary to this strategy, Sandars argued that it is vital to be open after an adverse event because this can provide an opportunity to help the patient try to understand what happened (p. 18).

\section{Conclusion}

In closing, the takeaway from this ethical dilemma of underreporting medical errors is that the healthcare industry will need to pool all of its resources to help create and sustain a high-community of trust, and this will require a deep understanding of how its stakeholders - the investors, employees, suppliers, customers and other affected communities - gauge trustworthiness (Hurley, 2013). Knowing this, as cited by Hurley (2013), this means that the healthcare industry will need to focus on their common values, aligned interests, benevolence, competence, predictability and integrity, and communication, which can all serve as a foundation towards not only building trust, but also to help improve the safety of its patients (p. 76).

Even though this is the case, at the end of the day, medical errors will continue to be an unfortunate and unavoidable aspect of medical practice because of the adage "To err is human". In addition, while many doctors talk about patient welfare, the truth of the matter is that many will not disclose medical errors, but let it be known that such behavior is not ethical. The final analysis is that the healthcare community must remain vigilant to protect the patients that look to them for quality care, and they must be aggressive towards holding healthcare professionals accountable to uphold ethical principles, which can only take place within a just culture.

\section{Reference}

Archer, S., Hull, L., Soukup, T., Mayer, E., Athanasiou, T., Sevdalis, S., \& Darzi, A. (2017). Development of a theoretical framework of factors affecting patient safety incident reporting: a theoretical review of the literature. Journal of Epidemiology and Community Health, 7(12), 1-16. https://doi.org/10.1136/bmjopen-2017-017155

Bell, S. K., White, A. A., Yi, J. C., Yi-Frazier, J. P., \& Gallagher, T. (2017). Transparency when things go wrong: Physician attitudes about reporting medical errors to patients, peers, and institutions. Journal of Patient Safety, 13(4), 243-248. https://doi.org/10.1097/PTS.0000000000000153

Bishop, A. C., \& Cregan, B. R. (2015). Patient safety culture: finding meaning in patient experiences. International Journal of Health Care Quality Assurance. 28(6), 595-610. 
https://doi.org/10.1108/IJHCQA-03-2014-0029

Davies, J. M., Hebert, P., \& Hoffman, C. (2003). The Canadian patient safety dictionary. Canadian Patient Safety Institute.

Edwin, A. K. (2009). Non-disclosure of medical errors an egregious violation of ethical principles. Ghana Medical Journal, 43(1), 34-39. https://doi.org/10.1007/BF02946551

Health and Safety Commission Advisory Committee on the Safety of Nuclear Installations. (1993). Organizing for Safety: Third Report of the ACSNI Study Group on Human Factors, HSE Books, Sudbury.

Heher, Y. K., \& Dintzis, S. M. (2018). Disclosure of harmful medical error to patients: A review with recommendations for pathologists. Advances in Anatomic Pathology, 25(2), 124-130.

Hurley, R. F., Gillespie, N., Ferrin, D. L., \& Dietz, G. (2013). Designing Trustworthy Organizations. Sloan Management Review, 54(4), 74-82.

Jeong, H., \& Lee, W. (2017). A strategy to overcome under-reporting issues of voluntary medication error reporting system: Computerized prescriber order entry as an example. Biometrics \& Biostatistics International Journal, 5(5), 1-8.

Kalender, Z. T., Tozan, H., \& Vayvay, O. (2020). Prioritization of Medical Errors in Patient Safety Management: Framework Using Interval-Valued Intuitionistic Fuzzy Sets. Healthcare, 8(265), 1-25. https://doi.org/10.3390/healthcare8030265

Kim, C. W., Myung, S. J., Eo, E. K., \& Chang, Y. (2017). Improving disclosure of medical error through educational program as a first step toward patient safety. BMC Medical Education, 17(1), 1-6.

Kohn, L. T., Corrigan, J. M., \& Donaldson, M. S. (1999). To err is human: building a safe health system. Institute of Medicine. Washington, DC: National Academies Press.

Lee, D., Hong, K. S., \& Kim, N. Y. (2016). Effects of hospital leadership, organizational systems, and ESWOS on medical error reduction. Service Business, 10(1), 159-177.

McMains, V. (2016). Johns Hopkins study suggests medical errors are third-leading cause of death in U.S. Johns Hopkins Magazine

Nagarajan, G., \& Shrieff, K. (2017). Role of management in medical errors - Marking and methods to improve safety and reduce errors to the healthcare organization - A theoretical prospective. MIM International Journal of Management Research, 3(1), 53-60

Nieva, V. F., \& Sorra, J. (2003). Safety culture assessment: a tool for improving patient safety in healthcare organizations. Quality and Safety Healthcare, 12(20), 17-23. https://doi.org/10.1136/qhc.12.suppl_2.ii17

Noble, D. J., \& Pronovost, P. J. (2010). Underreporting of patient safety incidents reduces health care's ability to quantify and accurately measure harm reduction. Journal of Patient 


\section{Macrothink \\ International Journal of Human Resource Studies \\ ISSN 2162-3058 2021, Vol. 11, No. 2}

Safety, 6(4), 247-50. https://doi.org/10.1097/PTS.0b013e3181fd1697

Patel, R. S., Bachu, R., Adikey, A., Malik, M., \& Shah, M. (2018). Factors Related to Physician Burnout and Its Consequences: A Review. Behavioral and Brain Sciences, 8(11), 1-7. https://doi.org/10.3390/bs8110098

Sandars, J., \& Cook, G. (2007). ABC of Patient Safety, Blackwell Publishing Ltd., Malden, MA.

Sorrell, J. M. (2017). "Ethics: Ethical issues with medical errors: Shaping a culture of safety in healthcare" OJIN: The Online Journal of Issues in Nursing, 22(2).

Ugur, E., Kara, S., \& Yildirim, S., \& Akbal, E. (2016). Medical errors and patient safety in the operating room. Journal of Pakistan Medical Association, 66(5), 593-597.

Wu, A., McCay, L., Levinson, W., Iedema, R., Wallace, G., Boyle, D., \& McDonald, T. (2017). Disclosing adverse events to patients: International norms and trends. Journal of Patient Safety, 13(1), 43-49. https://doi.org/10.1097/PTS.0000000000000107

Zineldin, M., Zineldin, J., \& Vasicheva, V. (2014). Approaches for reducing medical errors and increasing patient safety TRM, quality and 5 Qs method. TQM Journal, 26(1), 63-74. https://doi.org/10.1108/TQM-03-2012-0029

\section{Copyright Disclaimer}

Copyright for this article is retained by the author(s), with first publication rights granted to the journal.

This is an open-access article distributed under the terms and conditions of the Creative Commons Attribution license (http://creativecommons.org/licenses/by/4.0/). 